\title{
EFMI Working and Project Groups - Overview and Current Activities
}

\author{
Alexander Hörbst ${ }^{1}$, Patrick Weber ${ }^{2}$ \\ 1 EFMI Press and Information Officer, UMIT - Private University for Health Sciences, Medical \\ Informatics and Technology, Austria \\ ${ }^{2}$ EFMI President, Nice Computing, Le Mont-sur-Lausanne, Switzerland
}

\section{Current Working and Project Groups}

EFMI is a nonprofit organisation concerned with the theory and practice of Information Science and Technology within Health and Health Science in a European context. Apart from other activities EFMI's success heavily relies on the work been done by its working and project groups. Currently EFMI has 17 active working and project groups:

- CLIOMICS - Clinical ..omics

- EDU - Education in Health Informatics

- EHR - Electronic Health Records

- EVAL - Assessment of Health Information Systems

- HIIC - Health Informatics for Interregional Cooperation

- HIME - Health Information Management Europe

- HOFMI - Human and Organisational Factors of Medical Informatics

- IDR - Informatics for the Disabled and Rehabilitation

- LIFOSS -Libre/Free and Open Source Software in Health Informatics

- MCRO/MBDS - Casemix, Resources Management and Outcomes of Care

- MIP - Medical Image Processing

- NLU - Natural Language Understanding

- NURSIE - Nursing Informatics in Europe

- PCI - Primary Care Informatics

- PPD Personal Portable Devices

- SSE - Safety, Security and Ethics

- TRACE - Traceability of Supply Chains

\section{EFMI WG CLIOMICS}

Clinical ..omics

Chair:

Amnon Shabo

IBM research lab Haifa

E-mail:shabo@il.ibm.com

Co-Chair:

N.N..

http://www.EFMl.org

\section{Main Objectives:}

The Clinical ..omics working group (biomics, genomics, proteomics, ...) was accepted by EFMI at the 2012 council meeting in Pisa. Description and objectives will be finalised for the next council meeting in 2013. 


\section{EFMI WG EDU}

Education in Health Informatics

\section{Chair:}

John Mantas

Health Informatics Laboratory

Faculty of Nursing

University of Athens, Greece

E-mail:imantas@nurs.uoa.gr

\section{Co-Chair:}

Arie Hasman

Department of Medical Informatics

University of Amsterdam, The Netherlands

E-mail:a.hasman@amc.uva.nl

http://www.EFMl.org

\section{Main Objectives:}

- To disseminate and exchange information on Biomedical and Health Informatics (BMHI) programs and courses.

- To advance the knowledge of how BMHI is taught to health care professionals, to students in Europe

- To promote a database on programs and courses on BMHI education

- To produce international recommendations on BMHI education

- To support BMHI courses and exchange of students and teachers.

- To foster the accreditation of BMHI programmes in Europe.

\section{Recent and Future Activities:}

- Publication of further editions of Globalization of Health Informatics Education, Studies in Health Technology and Informatics, Edited by: E.J.S. Hovenga and J. Mantas, 276 pp., IOS Press, 2004.

- Publication of the Revised version of Educational Recommendations of IMIA. J. Mantas et al. Methods Inf Med. 2010 Jan 7; 49(2): 105-120. It was prepared by the Task Force chaired by the EFMI WG Chair on Education.

- Collection of data to update the database of programmes and courses on the WG website.

- Successful proposal under Marie Curie call of European Commission.It iInvolves University of Athens, Technical University of Madrid, Akdaniz University from Turkey, and Institutions from Jordan and Egypt. It aims to promote and establish Biomedical and Health Informatics programs and exchange of scientists in the field.

- Support to expand BMHI programmes in countries of Eastern Europe and Far East through TEMPUS initiatives (applications pending). Coordinators from Armenia and Jordan, respectively

- A work will be initiated and coordinated to provide meta-analysis of the implementation of the educational recommendations in the universities in Europe

- Accreditation process of BMHI programmes is being implemented in Europe. Cooperation for the accreditation process initiated by IMIA of programs across Europe. First programs that has been accredited is MSc in Health Informatics of the University of Eastern Finland and the University of Göttingen.

- Presentation of Accreditation process of BMHI programmes is planned to be done during the Medinfo2013 in Copenhagen.in Europe

\section{Main Objectives:}

The working group deals with the issue electronic health records in the different levels of development: case level, organisational level, regional level, national level, and international level. The Working Group supports

- Studies on specification, implementation, and promotion of standards for EHR

- Modelling of EHR architectures and interoperability

- Education on the EHR field

University of Regensburg Medical Center

E-mail: bernd.blobel@klinik.uni-regensburg.de

Co-Chair:

N.N.

hitp: //www.EFMl.org

\section{Recent and Future Activities:}

- Plan for an Engagement at EFMI STC 2012 (unfortunately, the WG was not among the EFMI WGs selected for an engagement at STC 2012)

- Submission of a Joint Workshop proposal to MIE 2012 in cooperation with the EFMI WGs PPD and SSE

- Organisation of a Joint Round Table Event on „Secure mobile devices and implants for realizing pHealth" at pHealth 2012, 26-28 June 2012 in Porto, Portugal, in cooperation with the EFMI WGs PPD and SSE

- WG Meeting at MIE 2012 


\section{EFMI WG EVAL}

Assessment of Health Information
Systems
Chair:
Elske Ammenwerth
UMIT - University for Health Sciences, Medical Informatics
and Technology
Hall in Tyrol, Austria
E-mail: elske.ammenwerth@umit.at
Co-Chairs:
Pirkko Nykanen
School of Information Sciences
Tampere University, Finland
E-mail: pirkko.nykanen@uta.fi
Jytte Brender
Dept. of Health Sciences and Technology
Aalborg University, Denmark
E-mail: iytte@brender.dk
http://EVAL.EFMl.info

\section{Main Objectives:}

- To foster interdisciplinary discussion on evaluation issues in health informatics.

- To support communication of experiences by organizing tutorials and workshops.

- To promote European networking on evaluation issues in health informatics.

\section{Recent and Future Activities}

- The working group continues its close collaboration with the IMIA Working Group onTechnology Assessment and Quality Development, mostly by joint publications and joint workshops and tutorials at international conferences. . The working group also started to discuss closer collaboration with the AMIA Working Group on Evaluation. Here, among others, joint updates on the health IT bibliography, joint webinars on health IT topics and a meeting during Medinfo2013 are planned.

- GEP-HI, the Guidelines for Good Evaluation Practice in Health Informatics, has been systems in health care.

- The paper of de Keizer NF, Talmon J, Ammenwerth E, Brender J, Rigby M, Nykänen P. Systematic Prioritization of the STARE-HI Reporting Items. An Application to Short Conference Papers on Health Informatics Evaluation. Methods Inf Med. 2011 Mar 4;50(3). was selected as "best paper" for the IMIA Yearbook of Medical Informatics 2012.

- A Poster presentation by Ammenwerth E, de Keizer N, Rigby MJ, Nykänen P, Talmon J, Brender J. Promoting Evidence-Based Health Informatics - A Decade of Effort was accepted for Evidence Live 2013 conference, 25. - 26.3.2013, Oxford, UK.

- During MIE2012, the working group participated in the following activities:

- Panel: Development of Indicators to Monitor Availability and Use of EHR, HIE and PHR Systems (C Nøhr, A Faxvaag, H Hypponen, S Vingtoft, A Walldius)

- Workshop: Developing quality indicators for IT interventions in health care $(\mathrm{N}$ de Keizer, E Ammenwerth, H. Hyppönen, M. Rigby)

- Oral presentation: Exploring a methodology for eHealth indicator development (H Hypponen, E Ammenwerth, $\mathrm{N}$ de Keizer)

- Oral presentation: eHealth indicators: results of an expert workshop (H Hypponen, E Ammenwerth, C Nohr, A Faxvaag, A Walldius)

- From MIE2012, the following publications of the working group appeared:

- Hyppönen H, Ammenwerth E, de Keizer N. Exploring a Methodology for eHealth Indicator Development. In: Mantas J et al (Eds.). Quality of Life through Quality of Information: Proceedings of Medical Informatics Europe 2012 (MIE 2012), Pisa, 26. - 29.8.2012. IOS Press. 2012. pp. 338 - 341.

- Hyppönen H, Ammenwerth E, Nohr C, Faxvaag A, Walldius A. eHealth-Indicators: Results of an Expert Workshop. In: Mantas J et al (Eds.). Quality of Life through Quality of Information: Proceedings of Medical Informatics Europe 2012 (MIE 2012), Pisa, 26. - 29.8.2012. IOS Press. 2012. pp. 328 - 332.

- The working group is working on explanation papers for STARE-HI and GEP-HI that will give further explanations and justifications as well as examples.

- The working group is coordinating a special issue on health IT evaluation for Artificial Intelligence in Medicine. From around 30 submissions, six have been pre-selected and are now undergoing a thorough review.

- The working group will submit an invited contribution to the IMIA Yearbook of Medical Informatics 2013.

- The working group is collaborating with the Nordic Council of Ministers eHealth group and OECD eHealth indicator task forces in testing the methodology for eHealth Indicator Development, which was published in 2012 by the Working Group. Information and progress on this collaboration is available at the project website (http://www.thl.fi/en_US/ web/en/research/projects/nordic_ehealth_research_network)

- The web-based health IT Evaluation Inventory was completely updated and expanded. It now comprises around 1.700 abstracts of evaluation papers in health informatics. It allows researchers from all over the world to submit papers for inclusions. The Evaluation Inventory database is available for free at http://evaldb.umit.at.

- All activities of the Working Group as visible at our website at http://iig.umit.at/efmi. 


\section{EFMI WG HIIC}

\author{
Health Informatics for Interregional \\ Cooperation \\ Chair: \\ Lacramioara Stoicu-Tivadar \\ University "Politehnica" Timisoara \\ Timisoara, Romania \\ E-mail: lacramioara.stoicu-tivadar@aut.upt.ro \\ Co-Chair: \\ N.N. \\ http://www.EFMl.org
}

\section{EFMI PG HIME}

Health Information Management Europe

Chair:

Rolf Engelbrecht

BMIG Ismaning

E-mail:PRE@BMIG.de

Co-Chair:

Angelika Händel

University of Erlangen

E-mail:Angelika.Haendel@uk-erlangen.de

hitpp://www.EFMl.org

\section{Main Objectives:}

- To promote exchange of information and experiences between actors in Europe, especially in developing regions

- To investigate the needs, opportunities and obstacles for e-health and to review and select from different education options for developing regions.

- To disseminate European and world-wide results and experiences across regions and between professionals

- To facilitate access to European groups and their facilities and outcomes by students and health professionals from developing regions

- To disseminate European and world-wide results and experiences across developing regions and professionals

\section{Recent and Future Activities:}

- SPC-Chair EFMI-STC 2011 Laško, Slovenia.

- Support for Serbia and Moldavia to relate to European documents and possibilities of financing of health informatics projects.

- Starting cooperation with the Hungarian Society of Medical Informatics at regional level, connecting Timisoara (RO) and Szeged (HU) as a starting point for educational and real process activities.

- Works for extended cooperation in the region (Serbia, Croatia, Slovenia, aso).

- Sustains a Master degree in Information Systems in Healthcare, as unique cooperation at regional level in the area between a Technical University and a Medical University in order to prepare specialized staff in healthcare informatics having different backgrounds.

- In April 2012 support of a presentation of the Romanian Society of Medical Informatics at Romedica Expo, Bucharest.

- Members of the WG will present 3 papers at MIE2012.

\section{Main Objectives:}

- To promote exchange of experience in development, implementation, education, and use of health record systems

- To promote exchange of standards in close co-operation with SDOs (standard development organisations) and institutions working in the field on national and European level.

- To investigate the needs, opportunities and obstacles for health information management.

- To disseminate results and experiences across EFMI members

- To facilitate access to European educational facilities and EFMI members

\section{Recent and Future Activities:}

- Supporting activities of EFMI, its members (resp. their national societies) and IFHIMA-Europe, especially MIE and STC conferences.

- Organising workshops on national and European level

- Initiation of a Forum using internet and other publication media.

- Making educational and promotional material available

- Support of STC2012 in Moscow

- Support of ICICTH 2012 conference in Samos

- Preparation of IFHIMA (International Federation of HIM associations) 2013 conference in Montreal 


\section{EFMI WG HOFMI}

Human and Organisational Factors of Medical Informatics

Chair:

Dr. Jos Aarts

Institute of Health Policy and Management

Erasmus University Rotterdam

PO Box 1738, 3000 DR Rotterdam, The Netherlands

E-mail: j.aurts@bmg.eur.nl

Co-Chair:

Dr. Marie-Catherine Beuscart-Zéphir

EVALAB-CERIM

Faculté de Médecine, Université de Lille 21

Place de Verdun, 59045 Lille Cedex, France

E-mail: mcheuscart@univ-lille2.fr

hitp://www.EFMl.org

\section{EFMI WG LIFOSS}

Libre/Free and Open Source Software in Health Informatics

Chair:

Thomas Karopka

Germany

E-mail: TKaropka@gmail.com

\section{Co-Chair:}

N.N.

http://www.EFMl.org

\section{Main Objectives}

- To organize workshops and tutorials dedicated to the WG topics at MIE conferences and other events

- To establish networks of people involved in human and organizational factors in the healthcare domain, and to learn about new developments and their activities

- To disseminate knowledge about human and organizational factors in medical informatics by various activities, such as conferences, educational events, publications.

- To encourage individuals to publish their research and other work in journals

\section{Recent Events:}

- A HOFMI sponsored panel "Should health information technology be regulated" has been held at MIE2012 in Pisa.

- Jos is elected chair of WG People and Organizational Issues of the American Medical Informatics Association (AMIA) for the period 2013-2014.

\section{Recent Publications:}

- A paper resulting from the workshop at MIE 2011 has been accepted for the International Journal of Medical Informatics special issue "Human factors and implementation of health information technology: comparing approaches across countries". The title of the paper is: "A comparative review of safety initiatives for national health information technology". It is available as article in press on the Elsevier Science Direct website (reference: Magrabi F, Aarts J, Nohr C, Baker M, Harrison S, Pelayo S, et al. A comparative review of patient safety initiatives for national health information technology. Int J Med Inform. 2012 Dec 18.).

\section{Future Activities:}

- On August 17 and 18, 2013 the conference "Context Sensitive health Informatics" (CShI) will be held in the Herlev Hospital in Copenhagen The next two-day conference will be held prior to Medinfo 2013 on August 17 - 18, 2013 in Copenhagen. The website is http://www.cshi2013. org. The proceedings will be published by IOS Press as part of their series "Studies in Health Technology and Informatics". The conference is endorsed by IMIA, EFMI and AMIA. The European SPC members, Dr. Marie-Catherine Beuscart-Zéphir (chair), Dr. Christian Nøhr, Dr. Monique Jaspers, Dr. Samantha Adams and Dr. Jos Aarts, are associated with WG HOFMI.

\section{Main Objectives:}

- to help replicate the success of free/libre and open source projects in the health informatics domain, in particular those within education, research, clinical practice and administration.

- to build a repository of knowledge about free/libre and open source developments of relevance to the health informatics domain.

- to develop an Open Source Market Place.

- to explore the implications of digital rights management, digital signatures, copyright and intellectual property issues.

- to liaise with other organisations and groups with related or similar objectives.

\section{Recent Activities:}

- Workshop at MIE2011 in Oslo Common Infrastructure Software for eHealth, Telemedicine and Ambient Assisted Living based on Open Source Software

- Co-organization of the International Workshop on E-Health in Emerging Economies IWEEE (http.iweee.org)

- Co-organization of the Free/Libre Open Source Software in Health Care (FLOSS-HC) track at Med-e-Tel (www.med-e-tel.eu)

- Workshop at MIE2012 in Pisa: "Free/Libre Open Source Software in Medical Informatics Research and Education" in cooperation with EFMI EDU WG

- Workshop at EFMI STC2012

\section{Future Activities:}

- Workshop at MEDINFO 2013 in Copenhagen

- Further collaboration with IMIA OS WG and other EFMI and IMIA WGs

- Co-organization of "Open Source Village" at Med-e-Tel 2013.

- Support the further development of MedFLOSS.org as a forum and open source in health care market place

- Workshop at MIE2014 in Instanbul 


\section{EFMI WG MCRO}

\author{
MBDS - Casemix, Resources \\ Management and Outcomes of Care \\ Chair: \\ Jacob Hofdijik \\ Partner in Casemix \\ Oudlaan 4 \\ 3515 GA Utrecht, The Netherlands \\ E-mail: :hofdijik@casemix.nl \\ Retired Chair: \\ F.H. Roger France \\ E-mail: francis@rogerfrance.com \\ Co-Chair: \\ N.N: \\ hitpp://www.EFMl.org
}

\section{Main Objectives:}

The focus of this working group is on systems to measure health care to promote better and more effective health care delivery. While the focus of Casemix Systems was limited to inpatient episodes, since the beginning of this century the episode approach is widening to the complete cycle of treating the health issue of patients. This requires an extension of the Dataset required to represent the issue of the patiënt and the chosen care and cure approach. The next challenge is to apply the approach to patients treated by multidisciplinary teams of care providers, including the active patient in the continuum of care. Since the involvement of EFMI in the ESF study on the Holistic Citizen-Centric Vision for Information and Communication Technologies to Support Individual Health, the objective of the working group has been extended to the domain of social and health care management. The concept of the Village of the Future, which requires linking IT with empathy. The WG focuses thus on continuity of care, the most cost effective delivery and most of all on the quality of care.

\section{Casemix Platform}

- The organisation of special topic conferences, workshops, Village of the future sessions, Teaching sessions in the European Region on MBDS, Case Mix and Severity of cases and their applications to Resource management and outcomes of care.

- The organisation of a network of national correspondents to create and maintain communication of up to date experiences and/or references in the member countries, including national uniform data sets, terminology, coding systems and patient classification methods for resource management and quality of care. The working group will develop to a global network of national representatives from other IMIA regions. A start will be made with at least a regional correspondent.

- The dissemination of results about informatics tools and telematics systems in this specific area among EFMI and IMIA affiliated members and participants to their meetings.

\section{Recent and Future Activities:}

- Submitted Village of the Future Medinfo 2013

- PCSI Summerschool 2013 June Talinn

- Accepted Village of the Future CBMS Porto May 2013

- Village of the Future Workshops Pisa 2012

- PCSI Summerschool in Talinn 2012

- Joint presentation at the PCSI conference in Montreal 2011 on the Innovation profile, using GS1 standards.

- Presentation at WoHIT Budapest, Infolac Conference in Mexico and at the Innovation Village at MIE2011.

- Special Session on Casemix during the STC2010 in Iceland on Casemix and Chronic Care.

- MIE2009 Joint Session with CONTSYS about Continuity of Case and Casemix tools for Chronic Disease Management.

- PCSI 2008 Lisbon, Workshop on Casemix and Chronic Disease Management.

- MIE2008 - Working group session on Casemix and Integrated Care, CHAINE Revisited 


\section{EFMI WG MIP}

\author{
Medical Image Processing \\ Chair: \\ Alexander Horsch \\ Institut für Medizinische Statistik und Epidemiologie \\ Technische Universität München, Munich, Germany \\ E-mail: alexander.horsch@tum.de \\ Dept. of Clinical Medicine \& Dept. of Computer Science \\ University of Tromsse, Tromso, Norway \\ E-mail: alexander.horsch@uit.no \\ Co-Chair: \\ Thomas Wittenberg \\ Fraunhofer Insititue for Integrated Circuits IIS \\ Dept. of Image Processing and Medical Engineering \\ E-mail:wbg@uis.fhg.de \\ http://www.efmi-wg-mip.net
}

\section{Main Objectives:}

- Support of communication and common attempts of academia and industry to increase quality of innovation, research and development in the field of medical image processing.

- Activities towards references image databases for medical image processing R\&D groups in order to support validation and evaluation of medical image processing methods and systems.

- Maintain the working group website and establish a web-based information system for European image processing groups and their current activities.

- Organise meetings and workshops at EFMI conferences and other events such as CARS and Medinfo conferences.

- Build and maintain close relationship with persons, groups, organisations and standardisation bodies related to the field.

\section{Recent and Future Activities:}

- CARS 2011 in Berlin, 24 June 2011 successfully organized the 3rd CADdemo@CARS demonstration workshop for Computer Aided Diagnosis systems with four demonstrations, a panel discussion, and ca. thirty participants. Moderator: A. Horsch. Panellists: P. Cerello (I), H. Fujita (J), K. Mori (J), R. Nishikawa (US), T. Wittenberg (D).

- At MIE 2011 in Oslo a panel on „Patient Empowerment and High-Tech Imaging and Biosignal-Based Procedures - Contradiction or Challenge?" has been organized as a joint activity together with IMIA WG Biomedical Pattern Recognition, as well as a WG business meeting.

- As an educational activity support of the 19th CATAI Winter Course of the University of La Laguna, Tenerife, Spain, in March 2011 with a lecture on „Diagnostic DICOM Images in 4G Mobile Phones".

- The WG Website www.efmi-wg-mip.net provides pertinent content such as reports, concepts, and presentations for the public. Basic information about the working group (mission, members, etc) is maintained on the EFMI website www.efmi.org.

- Further workshops and business meetings are envisaged for the upcoming EFMI conferences. The use of the working group's CSCW platform shall be intensified, along with more timely exchange of information among the working group members.

- Continuation of support of the CATAI winter courses.

\section{Main Objectives:}

- To organize events, such as workshops and conferences dedicated to NLP (Natural Language Processing) and related fields (semantics, information retrieval, text mining...) applied to the biomedical domain in a broad sense;

- Networking with persons and societies involved in natural language processing and text mining in the medical domain, especially in Europe, and to learn about their current developments and activities. To develop connections with experts in NLP applied to unrestricted domains and to participate to related events;

- To represent EFMI at IMIA WG6 and at AIME, as well as in biomedical and molecular biology forums (e.g. ISMB, International Society for BioCuration) and to lobby to promote EFMI's expertise to standards and policymakers (WHO, IHE-Europe, National Library and Medicine, ECDC, European Union) by for instance by helping to prepare strategic research agenda of research funding agencies;

- To develop and maintain capacity services in the field of biomedical natural language processing, text mining and information retrieval; in particular to bridge the gap between bio- and medical informatics.

\section{Recent and Future Activities:}

- Establish connections with leading EU initiatives in the do $\neg$ mains of analysis of Clinical Reports using text analytical instruments, such as DebugIT (http://www.debugit.eu/) and terminology-driven semantic interoperability, in particular epSOS (http://epsos.eu), the e-Health flagship project;

- Various capacity and infrastructures services, regularly maintained by the NLU working 


\section{EFMI WG NLU}

\section{(continued)}

\section{EFMI WG NURSIE}

\section{Nursing Informatics in Europe}

\section{Chair:}

Patrick Weber

Nice Computing

Ch. de Maillefer 37

CH-1052 Le Mont-sur-Lausanne

Switzerland

E-mail: patrick.weber@nicecomputing.ch

Co-Chair:

PD. Dr. Thomas Bürkle

Lehrstuhl für Medizinische Informatik

Universität Erlangen

Krankenhausstraße 12

D-91054 Erlangen, Germany

E-mail: thomas.buerkle@imi.med.uni-erlangen.de

http://www.nicecomputing.ch/nieurope group, have been launched and/or updated (new MEDLINE baseline for the EAGLi bio-medical question-answering engine: http://eagl.unige.ch/EAGLi/; new release of SNOMED for the SNOCat medical coding tool: http://eagl.unige.ch/SNOCat/; the Knowledge Authoring and Refinement Tool for Infectious Diseases: http://eagl.unige. $\mathrm{ch} / \mathrm{KART} /$; the list of services is available on the Bibliomics and Text Mining (BiTeM) resource pages on http://bitem.hesge.ch/list-resources;

- MIE2011 conference: the WG co-organized a workshop on "From an ontology framework standard to terminologies" (University of Saint Etienne, INSERM, WHO collaborating center for International Classifications in French Language, Royal College of Nursing of United Kingdom, University of Sydney, WHO-FIC network, The Catholic University of Korea,Seoul); the WG also participated in the DebugIT's village of the future event;

- In December 2011, members of the WG were invited to participate in Swiss-funded evaluation of EU e-Health policies with the support of the BAG (Bundesamt fur Gesundheit)

- In March 2012, the UniMed resource (http://research.isb-sib.ch/unimed/), which aimed at bringing the gap between genotypic and phenotypic description of genetic pathologies has been updated;

- A WG-endorsed workshop is under preparation and should be submitted to the MIE 2012 program committee ("Khresmoi's village of the future");

- Representatives of the NLU WG are actively participating in research project accepted and under preparation, including Innovative Medicine Initiative's projects;

- The working group will be present at the IHE Projectathlon/epSOS Connectathlon in May 2012 in Bern to present WG resources and capacity services in the field of terminology management.

\section{Main Objectives:}

- NURSIE has 18 country members and 10 associate members.

- To support nurses and nursing organizations in the European countries with information and contacts and the field of informatics.

- To offer nurses opportunities to build contact networks within the informatics field. This could be accomplished by arranging sessions, workshops and tutorials in connection with the Medical Informatics European (MIE) conferences or by arranging separate meetings.

- To support the education of nurses with respect to informatics and computing.

- To support research and developmental work in the field and promote publishing of achieved results.

\section{Recent and Future Activities:}

- At STC 2012 in Moscow we organized a dedicated session for the Russian nurses. For this event about 50 nurses from all part of Russia took part. Nurses in Russia are in difficult position: low salaries, no value given on their work, staffing shortage. The nursing association that organizes with us this event is very active in giving the nurses the place they need to have. In this context informatics is not well developed. Collaboration with European countries are in place but this reached few of the nurses needing help.

- At MIE 2012 in Pisa we had an administrative meeting and a very well attended session about nursing and informatics.

- I had the opportunity in attend Romanian national medical informatics "Romedinf" where I was asked to give a keynote speech about nursing and informatics in November. The nursing session was very valuable and gave a nice perspective for the future.

- In Italy I attend in November a one-day meeting region Piemonte about the perspective of using nursing workload evaluation system. I participate to a round table: "Different approaches and philosophies in the construction of health information systems for nursing". The second day I joined the Acendio meeting where I could give an overview about eHealth in Europe. 


\section{EFMI WG PCI}

\author{
Primary Care Informatics \\ Chair: \\ Simon de Lusignan \\ Clinical Informatics and Health Outcomes Research Group \\ Department of Health Care Management and Policy \\ University of Surrey, GU2 7XH, UK \\ E-mail: s.lusignan@surrey.ac.uk \\ Co-Chair: \\ N.N. \\ hitp:///www.EFMl.org
}

\section{Main Objectives}

The group aims to be a focus for people to from a primary health care background to come to EFMI conferences. We aim to put on events, generally workshops at EFMI meetings and use the outputs from these to create a submission to the following years IMIA Yearbook for Medical Informatics. We work in close collaboration with national and the IMIA primary care working group.

- The aim of the group is to promote and develop primary care informatics as a specialism within health informatics.

- The group aims to put on workshops, and where feasible visits to primary health care facilities, at EFMI conferences.

- Increase the peer review primary health care informatics literature.

- Our three current themes are: (1) How to model research studies based on routinely collected data; (2) Ontologically rich approached to case finding in routine data; (3) Methods for the direct observation of the use of technology in the clinical consultation.

\section{Recent Activities:}

- MEDINFO 2010 South Africa. The working group contributed to two workshops at this event - one on the use of the computer in the consultation and the second on the barriers to using routine data for international research. The outputs from this informed our submission to the IMIA Yearbook of Medical Informatics.2,3

- STC 2011 Slovenia. From these and the discussions post conference emerged a submission to the STC (Special Topic Conference) in Slovenia in 2011, and a further workshop at MIE in Oslo at the end of August 2011. We have begun to recognise that part of the standard approach to research studies using routine data should be to develop and model use cases for the study; (we have used Unified Modelling Language (UML) to do this and also constructed data flow diagrams (DFD). We are beginning to recognise that there are generic models for some types of study which can be represented using reference models. Our first versions of these can be found at: http://www.clininf.eu/refmodel/

- MIE 2011 Norway. We extended this work at our workshop at MIE in Oslo August 2011. The presentation from this workshop can be downloaded from the Clinical Informatics website at: http://www.clininf.eu/news/presentations/116-mie2011oslo-presentation.html

- EFMI STC 2012 Moscow: Two papers emanating from working group will be part of the conference. The working group chair has co-authored a paper with Prof Matthew Swindells (who holds a visiting chair at University of Surrey) and was previously head of the English National Programme for IT. Olga Dmitrieva presents work on how the English NHS Hospital Episode Statistics (HES) data can be used to explore variation in the quality of care.

- MIE 2012 Italy. We had a workshop to explore how we could improve the design of research and quality improvement studies using routine data by using ontologically rich approaches to identifying variables. The workshop objective is to develop consensus methods of consistent extraction and processing of data. The workshop will include brief presentations on: (1) Capturing context by defining the domain ontology; and definition of a reference terminology; (2) Modelling data and metadata mechanisms; (3) Formalisation and otology development tools; (4) Validation of data quality ontology; and (5) Governance framework. We carried out a post workshop modified Delphi exercise to define and model these components into a usable toolkit that can be made available through the working group.

Informatics in Primary Care remains the journal of choice for the working group. The publishers offer working group members a discount on subscriptions. http://www.ingentaconnect. $\mathrm{com} / \mathrm{content} / \mathrm{rmp} / \mathrm{ipc}$

\section{Future Activities:}

- EFMI STC Prague 2013: Workshop on detecting the miscoding, misclassification of diabetes.

- IMIA MEDINFO Conference 2013: We plan to run a workshop in collaboration with the IMIA PCI WG. 


\section{EFMI WG PPD}

\author{
Personal Portable Devices \\ Chair: \\ Lenka Lhotska \\ Department of Cybernetics \\ Faculty of Electrical Engineering \\ Cech Technical University \\ Prague, (zech Republic \\ E-mail: hootska@labe.felk.rvut.cz \\ Co-Chair: \\ Peter Pharow \\ Fraunhofer IDMT IIImenau, Germany \\ E-mail: peter.pharow@web.de \\ hitp://www.EFMl.org
}

\section{Main Objectives:}

After its transition from WG CARDS, EFMI Working Group (WG) Personal Portable Devices (PPD) aims at being a European competence center to watch ongoing activities and to provide knowledge to policy makers and architect designers involved in the deployment of projects related to personal (or personalized), portable devices (PPD) such as cards, tokens, wearable and portable devices, sensors and actuators, smart phones and pads, and similar technologies including advanced network infrastructures mainly in the domain of healthcare and welfare. WG PPD links its activities to the domain of Ambient Assisted Living by liaising with the IMIA WG on Smart Homes and AAL. A second domain of interest is the home care area with its requirements for bridging between formal and informal carers not only from the view of applied technology but also in terms of usefulness and usability.

Furthermore, WG PPD representatives are actively involved in standardization activities in various fields and domains including security, safety, management, ethics, medical devices, and sensor networks. Members of WG PPD undertake ambassadorial roles by participating in additional standards developing organizations in domains where aspects of personal portable (mobile) devices are addressed. That concerns ISO and CEN but also ETSI, IEC and IEEE, just to name a few.

Moreover, WG PPD actively supports the organization of meetings, tutorials, workshops, sessions, and seminars of various kinds to disseminate the WG achievements, and to exchange knowledge and information about any topic linked to the interest of the WG PPD members.

\section{Recent Activities:}

- Active participation of various WG members (by means of organizing sessions, presentations, demos, and posters) in planning and preparation of pHealth 2011 - The 8th International Conference on Wearable Micro and Nano Technologies for Personalized Health, June 29 - July 1, 2011, Lyon, France

- Preparation of, and participation in a joint workshop "Data Privacy Management in pHealth" at pHealth 2011 - The 8th International Conference on Wearable Micro and Nano Technologies for Personalized Health, June 29 - July 1, 2011, Lyon, France together with EFMI WG SSE

- Active participation of various WG members (by means of SPC participation, LOC, sessions, presentations, demos, posters, and proceedings) in planning and preparation of pHealth 2012 - The 9th International Conference on Wearable Micro and Nano Technologies for Personalized Health, June 26 - 28, 2012, Porto, Portugal

- Joint Workshop at MIE 2012 in Pisa in cooperation and close collaboration with the EFMI WGs SSE and EHR including an active participation of WG members in the workshop (preparation, presentations, paper)

- Joint Tutorial at MIE 2012 in Pisa in cooperation and close collaboration with the EFMI WGs SSE and her including an active participation of WG members in the tutorial (preparation, presentations, paper)

- WG Meetings at pHealth 2012 and at MIE 2012

- Participation in the UK's Digital Policy Alliance (DPA - EURIM) taskforce that is preparing a briefing document for Members of Parliament on TeleHealth and TeleCare.

\section{Future Activities:}

- Session proposal for Medtel 2012, December 2012, Usti nad Labem, Czech Republic

- Workshop proposal for EFMI STC 2013 in Prague, CZ (preparation, presentations, submission of paper)

- Active participation of WG members (by means of SPC participation, LOC, sessions, presentations, demos, posters, and proceedings) in planning and preparation of pHealth 2013 - The 10th International Conference on Wearable Micro and Nano Technologies for Personalized Health, June 2013, Tallinn, EE, and Helsinki, FI

- Joint Workshop at MedInfo 2013 in Copenhagen, DK, in cooperation and close collabo- 
EFMI WG PPD

(continued)

\section{EFMI WG SSE}

Security, Safety and Ethics

Chair:

Bernd Blobel

eHealth Competence Center

University of Regensburg Medical Center

Regensburg, Germany

E-mail: bernd.blobel@klinik.uni-regensburg.de

\section{Co-Chair:}

N.N.

http://www.EFMl.org ration with the EFMI WGs SSE and her including an active participation of WG members in the workshop (preparation, presentations, paper)

- Joint Tutorial at MedInfo 2013 in cooperation and close collaboration with the EFMI WGs SSE and her including an active participation of WG members in the tutorial (preparation, presentations, paper)

- Joint Workshop at MIE 2014 in Istanbul, TR, in cooperation and close collaboration with the EFMI WGs SSE and her including an active participation of WG members in the workshop (preparation, presentations, paper)

- Joint Tutorial at MIE 2014 in cooperation and close collaboration with the EFMI WGs SSE and her including an active participation of WG members in the tutorial (preparation, presentations, paper)

- Continuing participation in the UK DPA activities on TeleHealth and TeleCare.

- Plans to have WG PPD meeting at relevant EFMI events, pHealth events, and/or other events in Europe that are of interest for WG PPD members.

\section{Main Objectives:}

Speeding up the use of ICT for health care increases the challenge for trustworthiness, security and safety of solutions and infrastructure deployed. The WG aims to promote development, education and training on the field of security and privacy in health care. Close collaboration with other EFMI-WGs and beyond as well as with IMIA WG4 as for securing their ICT solutions for health care.

\section{Recent and Future Activities:}

- Organizational sponsor of the EFMI STC 2011 „E-salus trans confinia sine finibus e-Health Across Borders Without Boundaries", 14-15 April 2011, Laško, Slovenia (together with EFMI WGs SSE, HIIC and PCI). Results are published at IOS Press SHTI Vol. 165.

- Preparation of a Joint Workshop of EFMI WGs EHR, PPD, and SSE „Electronic Records Systems and Policies on the Move to Pervasive Care" at MIE 2011 in Oslo, Norway

- Workshop „Data Privacy Management in pHealth“ at pHealth 2011 - The 8th International Conference on Wearable Micro and Nano Technologies for Personalized Health, 29 June -1 July 2011, Lyon,

- Engagement at EFMI STC 2012

- Organisation of a Joint Round Table Event on „Secure mobile devices and implants for realizing pHealth" at pHealth 2012, 26-28 June 2012 in Porto, Portugal, in cooperation with the EFMI WGs PPD and EHR

- Submission of a Joint Workshop proposal to MIE 2012 in cooperation with the EFMI WGs PPD and EHR

- WG Meeting at MIE 2012 


\section{EFMI WG TRACE}

Traceability of supply chains

Chair:

Prof. Christian Lovis, MD MPH

University Hospital Geneva

Division of medical information sciences

Switzerland

E-mail: christian.lovis@hcuge.ch

\section{Co-Chair:}

Christian Hay

GSI Healthcare

E-mail:christian.hay@gsl.ch

http://www.EFMl.org

\section{Main Objectives:}

Traceability is an important aspect of health informatics covering a large spectrum of challenges. Traceability requires to identify actors, objects and locations and to draw interactions between these elements, time and processes. Traceability covers the logistic of care: human resources, items, devices, drugs, locations; the care, care providers, patients, care activities, community networks; and the secondary usage of data, for billing, public health, clinical research and governance; amongst others.

Traceability

- builds the link of information between supply chains, care processes, outcomes and financial flows.

- faces important challenges, such as entities identification, authentication and serialization

- implies to track and trace physical entities and linking these entities to virtualized information flows.

The major benefits of traceability are

- improving efficiency and safety of care processes, including the supply chain of drugs, devices, etc.;

- improved secondary usage of data for outcome research;

- enables measures against counterfeited drugs and devices.

\section{Recent Activities:}

The WG is growing. Several works have been undertaken in collaboration with GS1

- a series of conferences to raise awareness on the need to connect Supply Chain data and processes in the Health Informatics environment (for example the "Logistics day in Switzerland)

- mapping the GS1 system with the HL7-RIM model

- participation to a working group for the global identification of actors with GS1

- participation to the "Convergence" initiative at MIE2011 and at the EHR4CR WS Basel, 2012

\section{Future Activities:}

- Next WS to be held at the STC2013 meeting in Prague. 